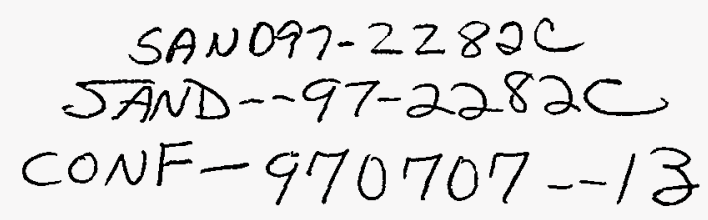

\title{
ADVANCES IN FERROELECTRIC POLYMERS FOR SHOCK COMPRESSION SENSORS
}

\author{
F. Bauer*, H. Moulard*, G. Samara** \\ *Institut Franco-Allemand de Recherches, (ISL), Saint-Lotis, France \\ ** Scondia National Laboratories, Albuquerque, NM 87185 USA
}

\begin{abstract}
Our studites of the shock compression response of PVDF polymer are continuing in order to understand the physical properties under shock loading and to develop high fidelity, reproducible, time-resolved dynamic stress gauges. New PVDF technology, new electrode configurations and piezoelectric analysis have resulted in enhancer precision gauges Our new standard ganges have a precision of better than $1 \%$ in electrical charge release under shock up to 15 GPa. The piezoelectric response of shock compressed PVDF gauges I $\mathrm{mm}^{2}$ in active area has suctied and yielded wellbehaved reproducible data up to $20 \mathrm{GPa}$. Analysis of the response of these ganges in the "thin mode regime " using a Lagrangian hydrocode will be presented. P(VDF-TrFE) copolymers exhibit unique piezcelectric properties over a wide range of temperature depending on the composition Their properties and phase transitions are being investigated. Emphasis of the presentation will be on key results and implications.
\end{abstract}

\section{INTRODUCTION}

Although ferroelectricity and piecoelectricity in Polyvinglidene Fluoride were discovered by Kawai (1) in 1969 and subsequently confirmed by Kepler (2), the materials commercially available did not exhibit reprochucible properties due to the critical importance of mechanical and electrical processing history. Subsequently, the mechanical and electrical processes noeded to achieve precisely known and reproducible electrical propenties were developed (3).

The availability of reproducible samples provides an opportumity to study the materials and to deseribe the piseoclectric response of PVDF under the destructive, very high pressure conditions achieved in controlled shock loading (4). Previous work (3) has shown that selected and precisely poled standard $9 \mathrm{~mm}^{2}$ PVDF gauges conld respond precisely to pressures of 25 GPa. For $1 \mathrm{~mm}^{2}$ ganges, at pressures up to $12 \mathrm{GPa}$, welldefinet signals are observed. Buil the usefulness of $1 \mathrm{~mm}^{2}$ PVDF ganges was hampered by observations of differences in responses even at low shock pressure.

The need to develop high fidelity, reproctucible time-resolved dynamic stress ganges especially with small active areas, has led us to continue these sudies of shock compression response of PVDF polymers, and to understand the physical properties under shock loading. The present paper will briefly summarize the advances in new poling technology, as well as the development of high fidelity, reproducible, time-resolved dynamic struss gauges with small areas. The shock induced polarization for 1 and $9 \mathrm{~mm}^{2}$ precisely poled gauges are 


\section{DISCLAIMER}

Portions of this document may be illegible in electronic image products. Images are produced from the best available original document. 


\section{DISCLAIMER}

This report was prepared as an account of work sponsored by an agency of the United States Government. Neither the United States Government nor any agency thereof, nor any of their employees, make any warranty, express or implied, or assumes any legal liability or responsibility for the accuracy, completeness, or usefulness of any information, apparatus, product, or process disclosed, or represents that its use would not infringe privately owned rights. Reference herein to any specific commercial product, process, or service by trade name, trademark, manufacturer, or otherwise does not necessarily constitute or imply its endorsement, recommendation, or favoring by the United States Government or any agency thereof. The views and opinions of authors expressed herein do not necessarily state or reflect those of the United States Government or any agency thereof. 
compared. The analysis of the response of these ganges and of standard PVDF ganges in the "thin mode regime" using a Lagrangian hydrocode has been revisited Effects of pressure on the tielectric propertics of P(VDR-TrFE) copolymers have been also investigated and will be summarized

\section{PROGRESS IN TECHYOLOCY}

In order to enhance the precision of the anges and to avoid some deviations in the gange response as reported before (3), we have developed new poling equipment. This equipment allows us to adjust, in teal time via a high voltage and data acquisition computer controlled system, the predetermined remanent polarization as yell as the maximum displacement current measured at the coercive field to an individual sample. Further, with appropriate attention to the history of each sample, space charge in the samples can be eliminated (3), (4). A higher degree of reproducibility is achieved when the maximum displacement current at the courcive field is stabilized. Each sample fabricated in this pross is characterized with an individual poling history with well-defined electrical properties, better than $2 \%$ which can be reproduced at will.

\section{HIGK PRESSURE APPARATUS: PRECISE IMPACT LOADING}

In the impact experiment the symmetry conditions for identical impactor and sample materials require that precisely one-half the velocity at impact be irparted to the sample. In the electrical measurenent circuit the expensive CVR is replaced by a CMS resistance. Sample response is determined by recording the short-circuited current during the time the shock waves are reverberating within the samples until mechanical equilibrium is achieved comesponding to the longiradinal stress in the standard material. The electrical charge is determined by nnmerical integration of the reconded current. A range of impact velocities from $0.25 \mathrm{~km} / \mathrm{s}$ to $1.8 \mathrm{~km} / \mathrm{s}$ are schicved with a powder gan which accelerates the projectile to a preselected velocity. PVDF samples are placed on the impact surfer of either $2-$ cun quartz, sapphirc crystals or selected copper which serve as the standard materials to define the stress. Typical times to achieve equilibrium in the 25 micron films are 50 to 150 nanaseconds

\section{PIEZOELECTRIC POLARIZATION AT PRESSURE}

Figure 1 shows the results of experiments to peak pressures of abour $12 \mathrm{GPa}$ for both $1 \mathrm{~mm}^{2}$ and $9 \mathrm{~mm}^{2}$ PVDF ganges. Data are shown for standard materials as well as those with the coppor, the fused quart ramp laxding or KelF impactors. Data for $1 \mathrm{~mm}^{2}$ PVDF including "Baricer pillow" isentropic loading (where the stress is measured simnltaneously with a $9 \mathrm{~mm}^{2}$ PVDF) are also sbown on the same Figure 1.

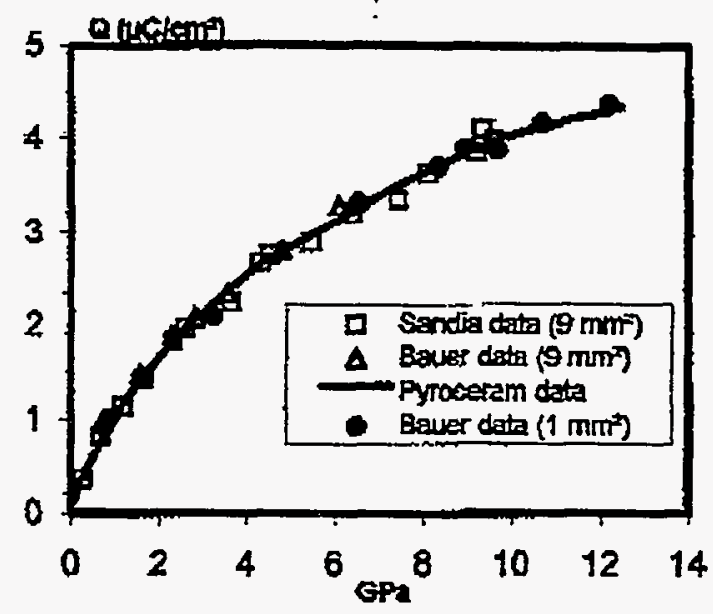

FIGURE 1, Oberved charge is sor bet for the yarious loating palks ghow that the final change is ind pondont of path it low stress the continuour rapunes dats is compared to shook reponse (3) (4).

The deviation of experimental points about their representative values is thought to be within the experimental oncertainty of the recording instruments and less than $1 \%$ in elcotrical change release. The behayior indicates a strongly nonlinear character. The shock induced polarization for both precisely poled ganges under shock loading is abserved to be identical. The expo- 
timental results are in excellent agreement with the Graham-Sandia data (4), and recalled here.

\section{LAGRANGIAN ANALYSIS}

Even though the piecoelectric polarization is observed to be continmousty nonlinear with stress (3), the obsenved polarization with the computed true strain of PYDF is non linear in the true strain values region $(0-0.03$ ), and appears to be approximately lineas in the range $(0.03-0.45)$. Figure 2 gives the electrical charge versus thue strain for both ISL and Sandia data (3)

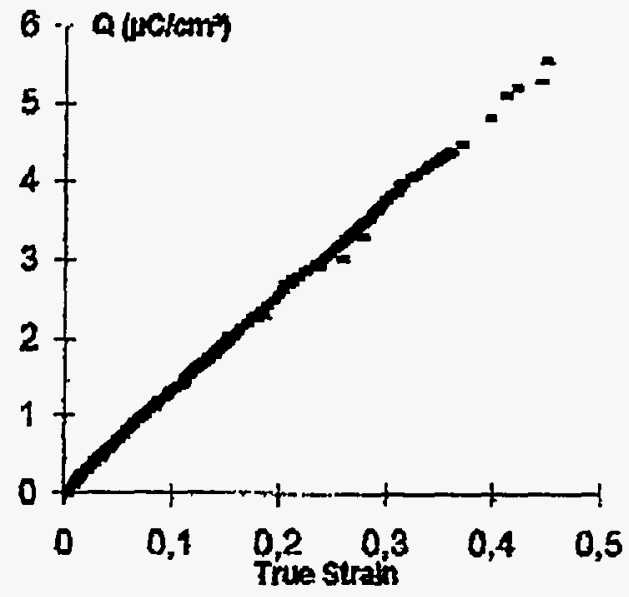

FIGURE 2. Eledriesl charg vs the computed true drain \&

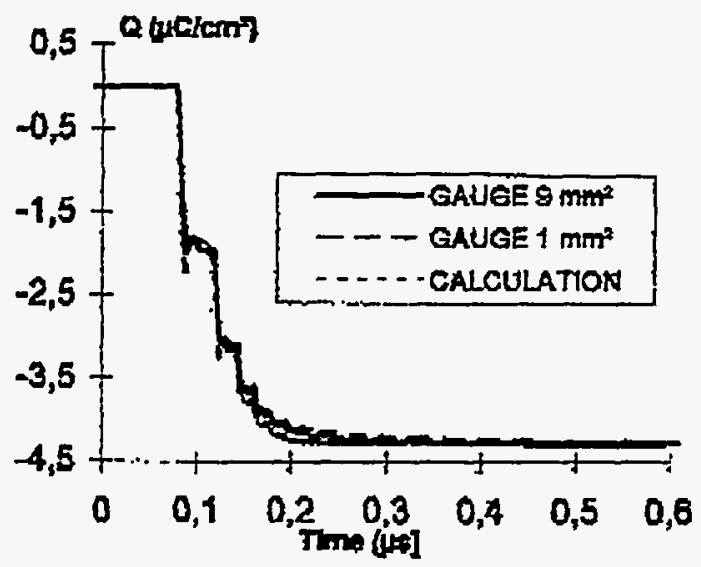

FIGURE 3. Cosparion between expecimantal and coroputed dats.
En introducing (5) the experimental (Q-6) relation into the hydrosede DYNA or SHYLAC, we can compute the theoretical current or charge profile for a given test. Figure 3 shows the compatarion-experiment comparisons for both I $\mathrm{mm}^{2}$ and $9 \mathrm{~mm}^{2}$ PVDF ganges in the same symmetric copper impact test (shock pressure : 12 GPa). The calculation allows is to deternine the stress too. We observe that the experimental and computed charge versus stress are in very good agreement with the pablished data (0 - $10 \mathrm{GPa}$ ) of R A Graham (4) on our PVDF ganges, Figure 4.

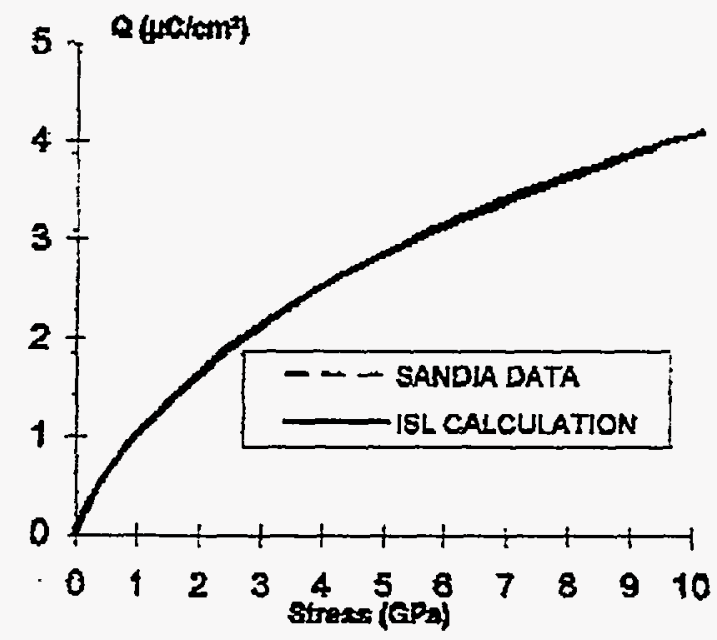

FIGURE 4. Experimental and compued there va tress.

$$
\text { P(NDF }{ }_{2,-T R E} \text { - COPOLYMERS }
$$

P(VDF-TYFE) copolymers (6) exhibit trilorable ferroelectric, piezoelectric and structural properties that may surperior to those of PVDF for some shock gauge applications, Consequently, we have been investigating these properties as functions of static and dynamic.pressure.

The phase diagram for P(VDF $0 . \pi \mathrm{TrFE}_{0.29}$ ) was determined from dielectric spectroscopy measurements as functions of temperature, hydrostatic pressure and frequency following established procedures (6). The important features in the phase space for PVDF and its copolymers are (with increasing temperature) a prominemt molecular relaxation process centered around 
$T_{\beta}=270 \mathrm{~K}$ and the melting transition $\left(T_{m}\right)$. In adtition the copolymers exhibit a ferroelectric transition $\left(T_{C}\right)$ below $T_{m}$ All of these transitions have strong influences on the electrical and mechanical responses of these polymers. The transition at $T_{\beta}, T_{C}$ and $T_{m a}$ are well-defined features in the real $\left(\varepsilon^{\prime}\right)$ and imaginary $\left(\varepsilon^{\prime \prime}\right)$ parts of the dielectric response, Figure 5. All of these features shift to higher temperatures with increasing pressure, as skown.

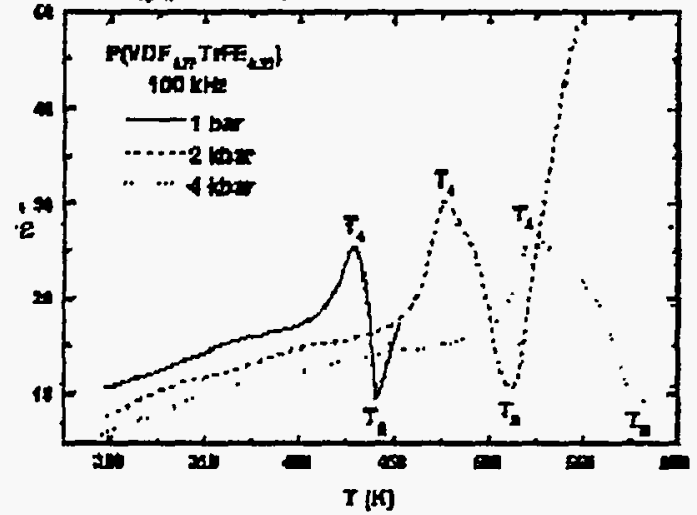

IIGURE 5. Real part of the dielearic conseant us temperate showing the large influenos of preserere on the various phase tremsition in the copolymer.

In Figure 6 , the initial slopes of the phase boundaries $d T_{x} / d P$ for $T_{\beta}, T_{C}$ and $T_{m}$ are $11 \pm 1$ (independent of frequency), $24 \pm 1$ and $41 \pm 1 \mathrm{~K} / \mathrm{kbar}$, respectively. The slope $\mathbf{d r}_{\beta} / \mathrm{dP}$ is the same as for PVDF. The slopes $\mathbf{d} T_{C} / \mathrm{dP}$ and $\sigma T_{m} / \mathrm{dP}$, exhibit strang dependence on composition (6). Specifically and for comparison, $\mathrm{dT} / \mathrm{dP}=30 \pm 2 \mathrm{~K} / \mathrm{k}$ tar for $\mathrm{P}\left(\mathrm{VDF}_{0.70} \mathrm{TrFE}_{0.30}\right)$ and $\mathrm{dT}_{\mathrm{t}} / \mathrm{dP}=29 \pm 2 \mathrm{~K} / \mathrm{kbar}$ for PVDF and 53.4K/har for P(VDF $0.70 \mathrm{TrFE}_{0.30}$. The melting curve of PVDF is the dashed curve, Fig. 6.

\section{CONCLUSION}

Advances in poling process of $1 \mathrm{~mm}^{2}$ and 9 $\mathrm{mm}^{2}$ PVDF gauges have been achieved. The shock incuced polarization for both precisely poled gauges sustained to shock loading greater than 12 GPa is observed to be identical. Computed data via numerical analysis are in good agrement with the experimental and pubijghed data. It is clear (6) that pressure strongly stabilizes the ferroelectric phase.
The electrical outuut of the gauge is deternined solely by the piezolectric response, i.e., there is essentially no cormain switching. The much larger $T_{m}(P)$ slope suggests that the copolymer may have advantages over PVDF for high pressure (>100kbar) applications. Shock experiments should be designed to avoid or take the strong relavetional response imto consideration.

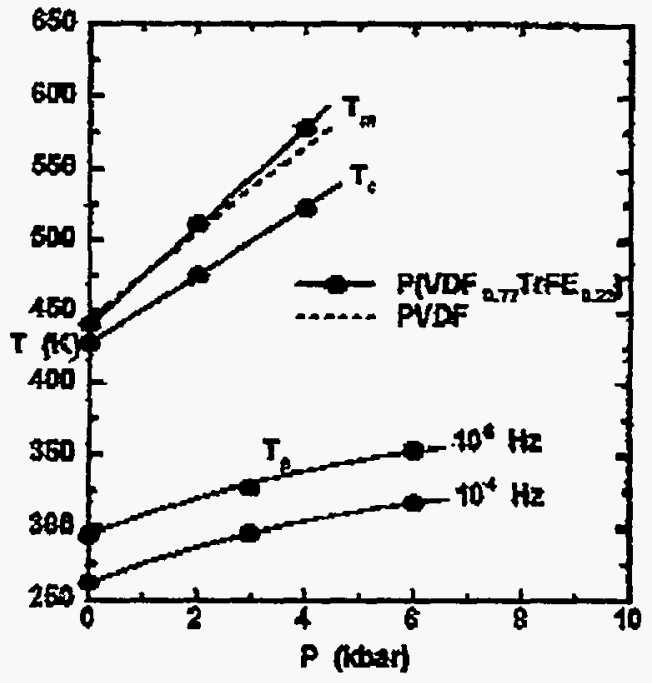

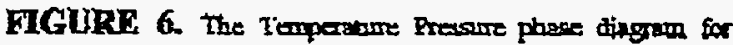
P(VDFanTiFEa2s).

\section{ACKNOWLEDGMENTS}

This work in ISL was supported by the DREI under Contract and in Sandia by the United States Department of Energy under Contract DE-ACO4 94AI85000. We express our appraciation to IS.L. and Sandir staffs.

\section{REXERENCES}

1. HL Batri, J. Appl Phys. \& pp 975, (1969)

2. R.G. Keplex, Ann Rev. Phpe (them 29, 497 (1978).

3. F. Bane sad R.A. Grahgm, Ferrosleatrics, 171, 95 (1995) and references therein.

4. RA. Griham, Solids under High Prossung Shock Compression New Yar: Spring Velog 1993, op 103-113.

5. H.Moulard, F. Bawer, Procectings of Shock Frowes it Condensed Matter. Nenth-Hollond po 106s-1068, 1995

6. G. A Samirs and F. Baver, Ferroelectrics, 135, 385 (1992) sad referoses therein. 